\title{
Effects of Three-dimensional Measurement of the Urinary Stone Size on the Surgical Outcomes of Retrograde Intrarenal Stone Surgery
}

\author{
(1) Batuhan Ergani1, (1) Zafer Kozacıoğlu² \\ ${ }^{1}$ Beyhekim State Hospital, Clinic of Urology, Konya, Turkiye \\ 2 Izmir University of Economics Medical Park Hospital, Clinic of Urology, İzmir, Turkiye
}

\section{What's known on the subject? and What does the study add?}

The main objective of this study was to measure stone size by calculating the stone volume owing to its three-dimensional configuration in space, instead of measuring the longest side in a single plane or calculating the stone area. The threshold values that were determined as significant parameters that affect stone-free status were the presence of one stone, stone size of $1.48 \mathrm{~cm}^{2}$, stone volume of $1.54 \mathrm{~cm}^{3}$ and $55 \mathrm{~min}$ of operation time. If determined by volume calculation, retrograde intrarenal surgery is an effective and reliable method for stones $<1.54 \mathrm{~cm}^{3}$.

\begin{abstract}
Objective: This study aimed to investigate peri-/postoperative effects of three-dimensional measurement of stone size in patients who underwent retrograde intrarenal surgery, where preoperative stone size calculations determine the operation decisions and prognosis. Another aim is to determine a limit value in $\mathrm{cm}^{3}$ for retrograde intrarenal surgery and to predict stone-free status based on this limit value.

Materials and Methods: Data of 184 patients were retrospectively analysed. Patients were divided into two groups according to whether the stonefree status was achieved. Postoperative stone-free status and related effective parameters were analysed statistically.

Results: No significant difference was found between age, gender, Hounsfield unit, length of hospital stay, secondary retrograde intrarenal surgery, renal unit abnormality, stone side, stone opacity, presence of additional ureteral stone, hydronephrosis and preoperative Double-J stent placement with stone-free rate. Subsequent interventions for residual stones, number of stones, stone sizes in $\mathrm{cm}^{2}$ and $\mathrm{cm}^{3}$ and operation time were determined as parameters that significantly affected the stone-free rate. As a result of the receiver operating characteristic analysis, the threshold stone size was $1.54 \mathrm{~cm}^{3}$.

Conclusion: More accurate indications can be determined by calculating the volume of the stone. Retrograde intrarenal surgery success decreases in stones $>1.54 \mathrm{~cm}^{3}$ by volume calculation. A different method such as percutaneous nephrolithotomy should be considered with higher preference for stones above this value.
\end{abstract}

Keywords: Kidney stone, retrograde intrarenal stone surgery, stone-free rate, stone volume

\section{Introduction}

Urinary system stone disease is one of the most important diseases that affect human health and social life. Its prevalence varies according to geographical regions. Stones can be seen in any structure along the urinary tract, but it is most common in the kidney. Current management of kidney stones includes follow-up, medical therapy, extracorporeal shock wave lithotripsy (ESWL), percutaneous nephrolithotomy (PNL), retrograde intrarenal surgery (RIRS), laparoscopy/robot and open surgery. At present, open surgery is required only in 1\%-2\% of the cases, and minimally invasive methods are preferred in most of the patients with stones, because of the new developments in medical technology and advances in endoscopic approaches $(1,2)$.

RIRS was defined by Fuchs in the early 1990s, and following publications of the first experiences with RIRS, flexible 
ureterorenoscopes were improved further in the last 15 years and used extensively with increasing success and decreasing complication rates (3). Along with the new developments in technology, flexible ureterorenoscopes are used in the treatment of kidney stones $<2 \mathrm{~cm}$, having higher mobility with increased deflection ability and providing higher image quality with fibre optic lighting, which are also smaller and relatively more durable. The use of holmium laser technology and nickeltitanium alloy baskets in endourology is the most important factor in the development of RIRS.

In the latest stone guides, stone size measurement that guides the treatment procedure is evaluated in a single plane, even if the kidney stones have three-dimensional (3D) configuration, and the treatment indication is determined according to this single plane measurement. We are concerned on whether the measurement of the longest axis is adequate or whether calculating the surface area in a single plane may give false results for each parameter that can affect success in kidney stone treatment modalities. Thus, in this study of patients who underwent RIRS for stone disease, we aimed to calculate stone volume considering the $3 \mathrm{D}$ configuration in space, compare results with those of patient who underwent RIRS with preoperative measurement of maximum stone size in one plane, and investigate the effects of that choice on the operation and patient, in the light of the literature and stone guide. In addition, we aimed to determine a limit value in $\mathrm{cm}^{3}$ for RIRS, based on volume calculations, and to predict stone-free status based on this limit value.

\section{Materials and Methods}

This study was carried out by reviewing data of patients who underwent RIRS for kidney stones in the urology clinic of our hospital between May 2013 and September 2017. Patients with horseshoe kidneys and ectopic/pelvic kidneys, patients aged $<18$ years, and those with missing preoperative and postoperative data were excluded from the study. Finally, 184 patients were included in the analysis.

The retrospective analysis of data was performed after obtaining the approval of the local ethics committee of our hospital (September 21, 2017; session no: 13 and decision no: 17). Verbal and written informed consent forms were obtained from all patients before the procedure.

The longest measurements in the axial, coronal and sagittal planes were used in calculating the stone size in computed tomography (CT) images. Area calculation was noted in $\mathrm{cm}^{2}$ by multiplying the lengths in the axial and coronal planes. The volume calculation in $\mathrm{cm}^{3}$ was performed using an ellipsoid formula as recommended by the European Association of Urology (EAU) guideline by multiplying the lengths in the three aforementioned planes and $3.14^{*} 0.167$ (stone volume $=3.14 \times$ width $\times$ length $\times$ height $\times 0.167$ ). In case of multiple stones, the dimensions of each stone were measured separately and then added. Postoperative stone-free status was evaluated by CT performed at the first month after RIRS. Absence of stones or stone fragments $\leq 4 \mathrm{~mm}$ was considered a stone-free status or clinically insignificant fragments, respectively (4).

General anaesthesia was administered in the supine position. A guidewire was placed into the target ureter, under the control of a C-arm fluoroscopy unit. The ureteral access sheath (9.5/11.5 Fr or 12/14 Fr and $35 \mathrm{~cm}$ or $45 \mathrm{~cm}$ hydrophilic-coated sheath) was inserted over the guidewire placed in the ureter to the ureteropelvic junction under fluoroscopic control. After entering through the ureteral access sheath with a flexible ureterorenoscope (Flex-X2, Karl Storz, Tuttlingen, Germany) with a 7.5-Fr outer diameter and upon observing the stone, lithotripsy was performed by Litho brand laser system, using 272- or 365- $\mu \mathrm{m}$ holmium laser probe with a frequency of 8-12 Hz and a power of 1.2-1.5 Joules. During the procedure, isotonic sodium chloride irrigation was performed to ensure imaging. Fluoroscopy control was initiated when the stones were completely fragmented. The time elapsed from insertion of the guidewire to the placement of the Double-J stent (DJS) was recognised as the operation time. DJS was placed in all patients after the procedure. DJSs were removed under local anaesthesia within 4 weeks after the surgery.

\section{Statistical Analysis}

Shapiro-Wilk test was used to test the normality of data distribution, and Levene's test was performed to assess the homogeneity of variance. Independent samples t-test, MannWhitney U test, Pearson's chi-square test and Fisher's exact test results were used in the comparison of factors that affect stone-free status. The cut-off values calculated for the stone number, stone size $\left(\mathrm{cm}^{2}\right)$, stone volume $\left(\mathrm{cm}^{3}\right)$ and operation time (min), which show significant relations with stone-free status, were analysed and expressed by receiver operating characteristic (ROC) analysis. The stone number, stone size $\left(\mathrm{cm}^{2}\right)$, stone volume $\left(\mathrm{cm}^{3}\right)$, operation time $(\mathrm{min})$ and presence of additional interventions were analysed according to the Naive Bayes classification in predicting stone-free status. Quantitative variables were shown as mean \pm standard deviation (minimum/ maximum) and median (minimum/maximum), and categorical variables as $n(\%)$. Variables were analysed at a 95\% confidence level, and p-value less than 0.05 was considered significant. SPSS 25.0 (IBM Corp., Armonk, NY, USA) package programme was used in the data analysis. 


\section{Results}

A total of 184 patients were included in the study; 68 were female (37\%) and 116 were male (63\%). Stone sizes ranged from $1 \mathrm{~cm}$ to $4 \mathrm{~cm}$. Demographic data, stone characteristics and peri-/ postoperative data are shown in Table 1. Total renal abnormality was determined in $25(13.7 \%)$ patients (renal malrotation in $12(6.6 \%)$ patients, solitary kidney in $10(5.5 \%)$ and bifid renal pelvis in $3(1.6 \%)$.

The median American Society of Anesthesiologists score was 2.

As regards the distribution of stones, $85(46.7 \%)$ patients had pelvic stones, $55(30.2 \%)$ had lower calyceal stones, 10 (5.5\%) had middle calyceal stones and 8 (4.4\%) had upper calyceal stones, while other cases had stones distributed to multiple sites, including the proximal ureter.

Clinically significant residual fragments remained in 64 (34.8\%) patients. Moreover, $49(76.6 \%)$ patients with residual stones were followed up, while the remaining 15 (23.4\%) underwent reoperation [in these patients, 3 underwent ESWL and subsequent PNL due to failure, 3 underwent PNL alone, 3 underwent ESWL alone, 4 underwent RIRC and 2 underwent ureterorenoscopy (URS)].

No significant relationship was found between the stonefree rate and factors that affect stone-free status, including age, gender, Hounsfield unit value of the stone, length of hospital stay, preoperative ESWL, preoperative $\mathrm{PNL}$, renal unit abnormality, stone side, stone opacity, accompanying ureter stone, hydronephrosis and preoperative DJS insertion. However, additional intervention to postoperative residual stones $(p<0.001)$, number of stone $(p=0.018)$, stone size in $\mathrm{cm}^{2}$ $(p=0.003)$, stone volume in $\mathrm{cm}^{3}(p=0.005)$ and operation time $(p=0.036)$ were significant parameters that affect stone-free status after RIRS (Table 2).

The threshold values determined as a result of the ROC analysis of the significant parameters that affect the stone-free status were as follows: presence of one stone, stone size of $1.48 \mathrm{~cm}^{2}$,

Table 1. Demographic data, stone characteristics and peri-/ postoperative data

\begin{tabular}{|l|l|l|}
\hline & Mean \pm SD & $\begin{array}{l}\text { Median (min/ } \\
\text { max) }\end{array}$ \\
\hline Age & $46.38 \pm 14.72$ & $47(18 / 83)$ \\
\hline Number of stones & $1.23 \pm 0.54$ & $1(1 / 4)$ \\
\hline HU value of stones & $1.043,70 \pm 354.65$ & $1100(300 / 1700)$ \\
\hline Stone size $\left(\mathrm{cm}^{2}\right)$ & $1.50 \pm 1.02$ & $1.3(0.25 / 8)$ \\
\hline Stone volume $\left(\mathrm{cm}^{3}\right)$ & $2.46 \pm 2.82$ & $1.68(0.24 / 25.02)$ \\
\hline Operation time $\left(\mathrm{min}^{3}\right)$ & $53.63 \pm 19.44$ & $50(25 / 145)$ \\
\hline Length of hospital stay (day) & $2.11 \pm 0.40$ & $2(1 / 4)$ \\
\hline HU: Hounsfield unit, SD: Standard deviation, Min: Minimum, Max: Maximum \\
\hline
\end{tabular}

Table 2. Factor affecting stone-free status

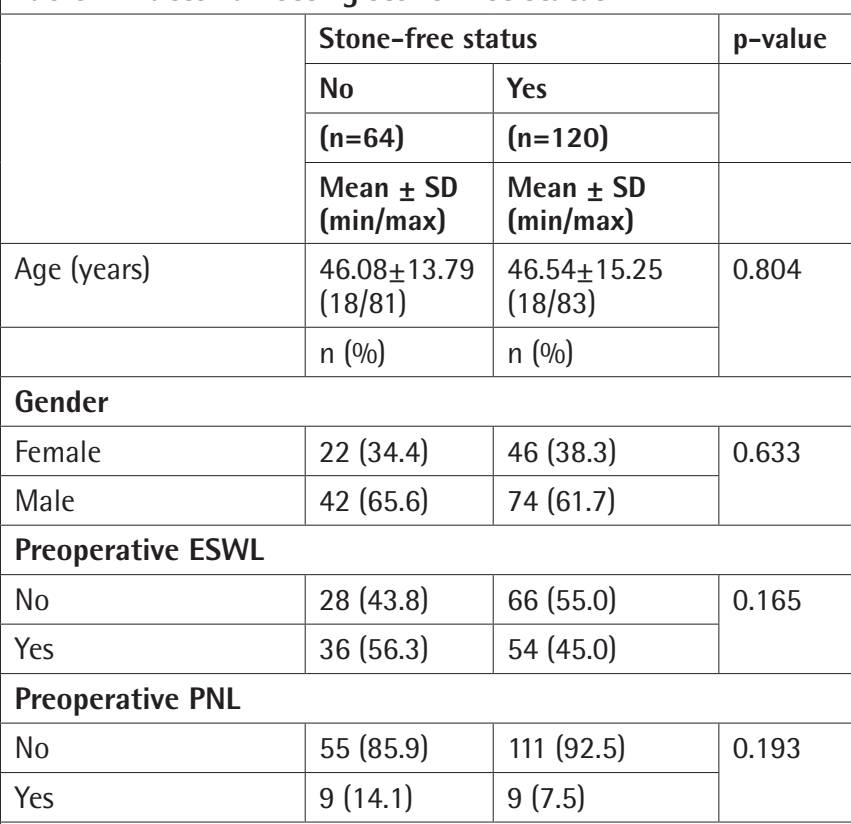

Abnormality in renal unit

\begin{tabular}{|l|l|l|l|}
\hline No & $51(81.0)$ & $106(89.1)$ & 0.174 \\
\cline { 1 - 3 } Yes & $12(19.0)$ & $13(10.9)$ & \\
\cline { 1 - 2 } Stone side & $36(56.3)$ & $64(53.3)$ & 0.757 \\
\cline { 1 - 3 } Left & $28(43.8)$ & $56(46.7)$ & \\
\cline { 1 - 2 } Right &
\end{tabular}

Stone opacity

\begin{tabular}{|l|l|l|l|}
\hline Opaque & $6(9.4)$ & $13(10.8)$ & \multirow{2}{*}{0.806} \\
\cline { 1 - 3 } Non-opaque & $58(90.6)$ & $107(89.2)$ & \\
\cline { 1 - 3 } Accompanying ureter stone &
\end{tabular}

Accompanying ureter stone

\begin{tabular}{|c|c|c|c|}
\hline No & $59(92.2)$ & $111(92.5)$ & \multirow[t]{2}{*}{1.000} \\
\hline Yes & $5(7.8)$ & $9(7.5)$ & \\
\hline \multicolumn{4}{|c|}{ Hydronephrosis } \\
\hline No & $23(35.9)$ & $56(46.7)$ & \multirow[t]{2}{*}{0.211} \\
\hline Yes & $41(64.1)$ & $64(53.3)$ & \\
\hline \multicolumn{4}{|c|}{ Preoperative DJS } \\
\hline No & $52(81.3)$ & $90(75.6)$ & \multirow[t]{2}{*}{0.459} \\
\hline Yes & $12(18.8)$ & $29(24.4)$ & \\
\hline \multicolumn{4}{|c|}{ Additional intervention for residual stone } \\
\hline No & $49(76.6)$ & $120(100.0)$ & $<0.001$ \\
\hline Yes & $15(23.4)$ & $0(0.0)$ & $\begin{array}{l}75.5(4.4- \\
1285.9)^{*}\end{array}$ \\
\hline \multicolumn{4}{|c|}{ Need for intensive care } \\
\hline No & $63(98.4)$ & 119 (99.2) & - \\
\hline \multirow[t]{2}{*}{ Yes } & $1(1.6)$ & $1(0.8)$ & \\
\hline & $\begin{array}{l}\text { Median } \\
(\min / \max )\end{array}$ & $\begin{array}{l}\text { Median (min/ } \\
\max )\end{array}$ & \\
\hline Stone number & $1.3(1 / 4)$ & $1(1 / 2)$ & 0.018 \\
\hline HU value & $\begin{array}{l}1200 \\
(300 / 1650)\end{array}$ & $\begin{array}{l}1000 \\
(300 / 1700)\end{array}$ & 0.244 \\
\hline
\end{tabular}




\begin{tabular}{|l|l|l|l|}
\hline Stone size $\left(\mathrm{cm}^{2}\right)$ & $1.53(0.45 / 8)$ & $1.24(0.25 / 4)$ & 0.003 \\
\hline Stone volume $\left(\mathrm{cm}^{3}\right)$ & $\begin{array}{l}2.37 \\
(0.45 / 25.02)\end{array}$ & $1.52(0.24 / 8.64)$ & 0.005 \\
\hline Operation time (min) & $50(30 / 125)$ & $45(25 / 145)$ & 0.036 \\
\hline $\begin{array}{l}\text { Length of hospital } \\
\text { stay (day) }\end{array}$ & $2(1 / 4)$ & $2(2 / 4)$ & 0.783 \\
\hline
\end{tabular}

ESWL: Extracorporeal shock wave lithotripsy, PNL: Percutaneous nephrolithotomy, DJS: Double J-stent, HU: Hounsfield unit, SD: Standard deviation, Min: Minimum, Max: Maximum; *Odss Ratio (95\% confidence interval)

\begin{tabular}{|c|c|c|c|c|c|}
\hline \multicolumn{6}{|c|}{$\begin{array}{l}\text { Table } 3 . \text { ROC analysis of parameters affecting stone-free } \\
\text { status }\end{array}$} \\
\hline & \multicolumn{2}{|c|}{ Stone-free status } & \multirow{3}{*}{$\begin{array}{l}\text { AUC } \\
\text { (sh) }\end{array}$} & \multirow{3}{*}{$p$-value } & \multirow{3}{*}{$\begin{array}{l}\text { Odss ratio } \\
(95 \% \mathrm{Cl})\end{array}$} \\
\hline & \multirow{2}{*}{\begin{tabular}{|l|} 
No \\
n (\%) \\
\end{tabular}} & \multirow{2}{*}{\begin{tabular}{|l|} 
Yes \\
n (\%)
\end{tabular}} & & & \\
\hline & & & & & \\
\hline \multicolumn{6}{|c|}{ Number of stones } \\
\hline$>1$ & $\begin{array}{l}18 \\
(28.1)^{* *}\end{array}$ & $17(14.2)$ & $\begin{array}{l}0.574 \\
(0.033)\end{array}$ & 0.024 & $\begin{array}{l}2.4 \\
(1.1-5.0)\end{array}$ \\
\hline$\leq 1$ & 46 (71.9) & $\begin{array}{l}103 \\
(85.8)^{*}\end{array}$ & & & \\
\hline \multicolumn{6}{|c|}{ Stone size $\left(\mathrm{cm}^{2}\right)$} \\
\hline$>1.48$ & $\begin{array}{l}38 \\
(59.4)^{* *} \\
\end{array}$ & $44(36.7)$ & $\begin{array}{l}0.635 \\
(0.042) \\
\end{array}$ & 0.001 & $\begin{array}{l}2.5 \\
(1.4-4.7)\end{array}$ \\
\hline$\leq 1.48$ & $26(40.6)$ & $76(63.3)^{*}$ & & & \\
\hline \multicolumn{6}{|c|}{ Stone volume $\left(\mathrm{cm}^{3}\right)$} \\
\hline$>1.54$ & \begin{tabular}{|l|}
47 \\
$(73.4)^{* *}$ \\
\end{tabular} & $59(49.2)$ & \begin{tabular}{|l|}
0.634 \\
$(0.042)$ \\
\end{tabular} & 0.001 & $\begin{array}{l}2.9 \\
(1.5-5.5) \\
\end{array}$ \\
\hline$\leq 1.54$ & $17(26.6)$ & $61(50.8)^{*}$ & & & \\
\hline \multicolumn{6}{|c|}{ Operation time (min) } \\
\hline$>55$ & \begin{tabular}{|l|}
28 \\
$(43.8)^{* *}$ \\
\end{tabular} & $33(27.5)$ & $\begin{array}{l}0.596 \\
(0.043) \\
\end{array}$ & 0.027 & $\begin{array}{l}2.1 \\
(1.1-3.9) \\
\end{array}$ \\
\hline$\leq 55$ & 36 (56.3) & $87(72.5)^{*}$ & & & \\
\hline
\end{tabular}

stone volume of $1.54 \mathrm{~cm}^{3}$ and 55 min of operation time. The stone-free rate decreased significantly as these values increased. The main objective of this study was to measure the stone size by calculating the stone volume owing to its $3 \mathrm{D}$ configuration in space, instead of measuring the longest side in a single plane or calculating the stone area. In our opinion, the true stone size can only be determined by volume calculation. In accordance with this objective, the results of the ROC analysis and the area under the ROC curve (AUC) supported our hypothesis. The parameter that determines the stone-free rate with the highest AUC value and odds ratio was the stone volume $\left(\mathrm{cm}^{3}\right)$ (Table 3).

According to the multiple logistic regression model, a stone-free status can be estimated significantly $(p<0.001)$ with an overall accuracy rate of $74.5 \%$, based on the threshold values calculated by the ROC analysis. Stone-free status can be predicted with an odds ratio of 2.5 if the stone volume $\left(\mathrm{cm}^{3}\right)$ is below the specified threshold value and with an odds ratio of 2.9 if the operation time is shorter than the specified threshold value (Table 4).

The parameters that significantly affect stone-free status were examined according to the Naive Bayes classification model, and these parameters had general accuracy of $78.8 \%$ to predict stone-free status. According to these results, the parameter of "additional intervention needed for postoperative residual stones" displayed the highest power to predict stone-free status, with respect to the Bayesian Information Criterion (BIC) and Rank score. However, this is a highly predictable situation that would not require any statistical analysis. "Stone volume calculation in $\mathrm{cm}^{3 \prime}$ is another parameter having the highest predictive power according to the BIC and Rank score. This is followed by the parameters of "stone size measurement in $\mathrm{cm}^{22}$, "operation time" and "number of stones" (Table 5).

Table 4. Prediction rate of stone-free status according to the multiple logistic regression model

\begin{tabular}{|c|c|c|c|c|c|c|}
\hline & \multirow{2}{*}{ b } & \multirow{2}{*}{ SE } & \multirow{2}{*}{ p-value } & \multirow{2}{*}{$\begin{array}{l}\text { Odss } \\
\text { ratio }\end{array}$} & \multicolumn{2}{|c|}{$\begin{array}{l}95 \% \text { Confidence } \\
\text { interval for odds }\end{array}$} \\
\hline & & & & & $\begin{array}{l}\text { Lower } \\
\text { limit }\end{array}$ & $\begin{array}{l}\text { Upper } \\
\text { limit }\end{array}$ \\
\hline $\begin{array}{l}\text { Stone size } \\
\mathrm{cm}^{3}(\leq 1.54)\end{array}$ & -0.933 & 0.381 & 0.014 & 2.5 & 1.2 & 5.4 \\
\hline $\begin{array}{l}\text { Operation } \\
\text { time (min) } \\
(\leq 55)\end{array}$ & -1.067 & 0.366 & 0.004 & 2.9 & 1.4 & 6.0 \\
\hline \multicolumn{7}{|c|}{$\begin{array}{l}\text { Prediction rate; Stone-free status (Yes) }=98.3 \% \quad(\mathrm{No})=29.7 \% \\
\text { Overall accuracy }=74.5 \% \text { P-model }<0.001\end{array}$} \\
\hline
\end{tabular}

Table 5. Predictive power of stone-free status according to the naive bayes classification model

\begin{tabular}{|l|l|l|l|}
\hline Predicting Parameter & Rank & BIC & $\begin{array}{l}\text { Average } \\
\text { log- } \\
\text { likelihood }\end{array}$ \\
\hline $\begin{array}{l}\text { Additional intervention for residual } \\
\text { stones }\end{array}$ & 5 & 0.567 & -0.553 \\
\hline Operation time (min) & 2 & 0.520 & -0.492 \\
\hline Stone number & 1 & 0.509 & -0.466 \\
\hline Stone size $\left(\mathrm{cm}^{2}\right)$ & 3 & 0.521 & -0.464 \\
\hline Stone volume $\left(\mathrm{cm}^{3}\right)$ & 4 & 0.540 & -0.469 \\
\hline Predion & \multicolumn{2}{|c|}{ rate; } &
\end{tabular}

Prediction rate; Stone-free status (Yes) $=100 \%($ No) $=39.1 \%$ Overall accuracy 78.8\%, BIC: Bayes information criterion

\section{Discussion}

The main aim of kidney stone management is to achieve complete stone-free status with minimal damage to the patient. Stone fragments remaining in the kidney after treatment may be a source of new stones causing new symptoms once again as well as provide a basis for infection. In the era where open stone 
surgery was performed, complete stone-free status was usually attained, and in those days, no difference was found in the definitions of surgical success. However, at present, minimally invasive techniques are developed, and some disagreements are observed in the definition of success (5-7).

In the literature, the average success rate of RIRS for lower pole stones in a single session is 86\% (8). In a study of 185 patients with kidney stones $\geq 2 \mathrm{~cm}$, Sari et al. (9) reported a success rate of $73.5 \%$ after the first RIRS and $85.4 \%$ in a multistaged approach. Preminger (10) reported a stone-free rate of $85 \%$ after the third month in patients who underwent RIRS for lower calyceal stones $<2 \mathrm{~cm}$. In another study, the early postoperative stone-free rate and success rate of RIRS in all localisations were $69.7 \%$ and $80.3 \%$, respectively, and high stone-free rates were reported, especially for small stones (11). Palmero et al. (12) reported a success rate of $73.6 \%$ after RIRS. The total success rate after additional procedures was $93.5 \%$ in the same study. In our study, early stone-free status rate was approximately $65 \%$, which is close to literature data. This result was achieved by a single procedure and determined by CT within one month after surgery, and it is obvious that even higher rates of stonefree status would be expected with additional treatments and in control films within three months after surgery. Thus, our success rate increased to 74\% when the secondary procedures were performed on 15 patients in whom a stone-free status could not be achieved. When the literature and our study data were evaluated, we can speculate that the most important reason for these variations in success rates is the measurement and consequent indication errors owing to the failure of calculating the stone volume.

The properties of post-RIRS residual stones were examined by Fabrizio et al. (13) in a study of 100 patients, and they observed that the proportion of patients with residual stones increased as the stone size increased. Among parameters that affect the success of RIRS, stone size was significant. To the best of our knowledge, this is the first study to have calculated the stone volume in evaluating RIRS success and where a threshold value is given, considering the whole literature or the EAU guideline and advising the longest measurement of stone size in a single plane or area calculation. The success rate of RIRS decreased in stones larger than $1.54 \mathrm{~cm}^{3}$, with a highly predictive power and prediction rate of stone-free status, according to our study that centred on the hypothesis that stone measurement should be made by volume calculation owing to its 3D structure in space, namely, width, length and height. Based on this data, more accurate indications can be determined in patients with urinary stone as a result of measuring the stone size and volume to increase the surgical success.

Lim et al. (11) categorised RIRS indications into primary and secondary RIRS. Patients who had unsuccessful ESWL and PNL treatments constituted the secondary RIRS group, and the vast majority of them were patients who underwent ESWL (32 ESWL/4 PNL). They found significant difference in the stonefree rates between the secondary RIRS group and primary RIRS group, in favour of patients who underwent primary RIRS. Other studies have reported that RIRS was an effective and reliable method in ESWL-resistant stones $(14,15)$. In our study, preoperative unsuccessful ESWL and PNL treatments did not affect the success in the secondary RIRS group.

Elbir et al. (16) concluded that the number of stones was an important parameter that affects the success of RIRS. According to their findings, RIRS success decreased statistically when the number of stones exceeded 1. In another study, the initial and final stone-free rates decreased significantly as the number of stones increased. Residual stones were significantly higher in the first day and first month after surgery in cases with multiple stones (17). Our results were similar to those of the literature, and we found that the number of stones was a parameter that effectively affects RIRS success. According to the ROC analysis, the surgical success decreased significantly as the number of stones exceeded 1. Stone number is a robust parameter in predicting stone-free status according to BIC and Rank score.

Kirac et al. (18) reported that the mean operation time was $66.4 \pm 15.8 \mathrm{~min}$ and the duration of hospitalisation was $24.5 \pm 4.6$ hours in patients who underwent RIRS. In our study, the average operation time was $45 \mathrm{~min}$ in the stone-free group and $50 \mathrm{~min}$ in the non-stone-free group. The mean operation time was shorter than the values reported in the literature for both groups, suggesting a significant difference in determining stone-free status. Moreover, the stone-free status significantly decreased in procedures longer than 55 min based on the ROC analysis. This result can explain the shorter operation time achieved in the stone-free group. A decrease in stone-free rates along with the increase in the operation time may be attributed to the lack of surgical experience, increased complication rates in cases with prolonged operation time and difficult localisation of the stones, such as the lower calyx, that may cause decreased manoeuvrability of the flexible URS and consequent fatigue and attention problem experienced by the surgeon. Moreover, our results revealed that operation time $<55$ min was an important parameter that can predict stone-free status with a high predictive power and rate. The length of hospital stay was 48 hours in the groups with and without stone-free status, which was a longer period when compared with literature data and had no significance in determining stone-free status.

Preoperative DJS placement was reported to increase stone-free rate by dilating the ureter, in a retrospective study that evaluated preoperative DJS placement for passive dilatation purposes due to reasons such as anuria or pyelonephritis (9). Another study pointed out the absence of no consensus on preoperative DJS 
placement for additional operation and the lower occurrence of urinary system complications of DJS (19). However, in our study, preoperative DJS had no effect on the success of RIRS. These data suggest that preoperative DJS placement for passive dilatation in patients undergoing RIRS was not effective in providing stone-free status, contrary to various reports. Thus, there will be less additional procedures, less cost, less morbidity and less emergency room admissions.

\section{Study Limitations}

This study has some limitations. Apart from the retrospective design, which is the main limitation, a standard volume calculation could not be performed (the lack of a software that can calculate the stone volume) because of the specific configuration of each stone, and procedures were performed by several surgeons with varying skills and experiences.

\section{Conclusion}

RIRS, one of the minimally invasive endourological techniques, is increasingly performed in the treatment of kidney stones. Our findings suggest that a more accurate indication can be determined by calculating stone volume instead of measuring stone size on a single plane. If determined by volume calculation, RIRS is an effective and reliable method for stones $<1.54 \mathrm{~cm}^{3}$. Regardless of the measurements in a single plane, another minimally invasive endourological method such as PNL should be prioritised in stones with a volume $>1.54 \mathrm{~cm}^{3}$. We believe that our results, supported by the data of other studies, will provide a new milestone in stone surgery and shed light on guidelines.

\section{Acknowledgments}

We thank Prof. Yusuf Özlem İlbey for his contribution and moral support.

\section{Ethics}

Ethics Committee Approval: The retrospective analysis of data was performed after obtaining the approval of the local ethics committee of our hospital (September 21, 2017; session no: 13 and decision no: 17).

Informed Consent: Verbal and written informed consent forms were obtained from all patients before the procedure.

Peer-review: Externally peer-reviewed.

\section{Authorship Contributions}

Surgical and Medical Practices: B.E., Z.K., Concept: Z.K., Design: B.E., Data Collection or Processing: B.E., Analysis or Interpretation: B.E., Z.K., Literature Search: B.E., Z.K., Writing: B.E.
Conflict of Interest: No conflict of interest was declared by the authors.

Financial Disclosure: The authors declare that they have no relevant financial.

\section{References}

1. Borofsky MS, Lingeman JE. The role of open and laparoscopic stone surgery in the modern era of endourology. Nat Rev Urol 2015;12:392-400.

2. Osman MM, Gamal WM, Gadelmoula MM, Safwat AS, Elgammal MA. Ureteroscopic retrograde intrarenal surgery after previous open renal stone surgery: initial experience. Urol Res 2012;40:403-408.

3. Fuchs GJ, Fuchs AM. Flexible Endoskopie des oberen Harntraktes. Eine neue minimal invasive Methode für Diagnose und Behandlung [Flexible endoscopy of the upper urinary tract. A new minimally invasive method for diagnosis and treatment]. Urologe A 1990;29:313-320.

4. Türk C, Neisius A, Petrik A, Seitz C, Skolarikos A, Thomas K. EAU Guidelines on Urolithiasis. European Association of Urology Limited Update 2018.

5. Porfyris 0, Delakas D. Post-extracorporeal shockwave lithotripsy residual stone fragments: clinical significance and management. Scand J Urol Nephrol 2012;46:188-195.

6. Ozgor F, Simsek A, Binbay $M$, Akman $T$, Kucuktopcu O, Sarilar O, Muslumanoglu AY, Berberoglu Y. Clinically insignificant residual fragments after flexible ureterorenoscopy: medium-term follow-up results. Urolithiasis 2014:42:533-538.

7. Palmero JL, Miralles J, Garau C, Nuño de la Rosa I, Amoros A, Benedicto A. Retrograde intrarenal surgery (RIRS) in the treatment of calyceal diverticulum with lithiasis. Arch Esp Urol 2014;67:331-336.

8. Li Z, Lai C, Shah AK, Xie W, Liu C, Huang L, Li K, Yu H, Xu K. Comparative analysis of retrograde intrarenal surgery and modified ultra-mini percutaneous nephrolithotomy in management of lower pole renal stones (1.5-3.5 cm). BMC Urol 2020;20:27.

9. Sari S, Ozok HU, Cakici MC, Ozdemir H, Bas O, Karakoyunlu N, Sagnak L, Senturk $A B$, Ersoy H. A Comparison of Retrograde Intrarenal Surgery and Percutaneous Nephrolithotomy for Management of Renal Stones ?2 CM. Urol J 2017;14:2949-2954.

10. Preminger GM. Management of lower pole renal calculi: shock wave lithotripsy versus percutaneous nephrolithotomy versus flexible ureteroscopy. Urol Res 2006;34:108-111.

11. Lim SH, Jeong BC, Seo SI, Jeon SS, Han DH. Treatment outcomes of retrograde intrarenal surgery for renal stones and predictive factors of stone-free. Korean J Urol 2010;51:777-782.

12. Palmero JL, Durán-Rivera AJ, Miralles J, Pastor JC, Benedicto A. Comparative study for the efficacy and safety of percutaneous nefhrolithotomy (PCNL) and retrograde intrarenal surgery (RIRS) for the treatment of 2-3,5 cm kidney stones. Arch Esp Urol 2016;69:67-72.

13. Fabrizio MD, Behari $A$, Bagley DH. Ureteroscopic management of intrarenal calculi. J Urol 1998;159:1139-1143.

14. Chung DY, Kang DH, Cho KS, Jeong WS, Jung HD, Kwon JK, Lee SH, Lee JY. Comparison of stone-free rates following shock wave lithotripsy, percutaneous nephrolithotomy, and retrograde intrarenal surgery for treatment of renal stones: A systematic review and network meta-analysis. PLoS One 2019;14:0211316.

15. Shim M, Park M, Park HK. The efficacy of performing shockwave lithotripsy before retrograde intrarenal surgery in the treatment of multiple or large $(\geq 1.5 \mathrm{~cm})$ nephrolithiasis: A propensity score matched analysis. Investig Clin Urol 2017;58:27-33. 
16. Elbir F, Başıbüyük i, Topaktaş R, Kardaş $S$, Tosun $M$, Tepeler A, Armağan A. Flexible ureterorenoscopy results: Analysis of 279 cases. Turk J Urol 2015;41:113-118.

17. De $\mathrm{S}$, Autorino R, Kim FJ, Zargar H, Laydner H, Balsamo R, Torricelli FC, Di Palma C, Molina WR, Monga M, De Sio M. Percutaneous nephrolithotomy versus retrograde intrarenal surgery: a systematic review and meta-analysis. Eur Urol 2015;67:125-137.

18. Kirac M, Bozkurt ÖF, Tunc L, Guneri C, Unsal A, Biri H. Comparison of retrograde intrarenal surgery and mini-percutaneous nephrolithotomy in management of lower-pole renal stones with a diameter of smaller than 15 mm. Urolithiasis 2013;41:241-246.

19. Silay MS, Tanriverdi O, Miroglu C. Re: Preoperative stenting decreases operative time and reoperative rates of ureteroscopy (from: Chu L, Sternberg KM, Averch TD. Preoperative stenting decreases operative time and reoperative rates of ureteroscopy. J Endourol 2011;25:751-754). J Endourol 2012;26:75-76. 